\title{
Adubação potássica e seu efeito residual sobre a produtividade e a qualidade de tubérculos de batata
}

\author{
Heider Rodrigo Ferreira Silva(1) e Paulo Cezar Rezende Fontes ${ }^{(1)}$
} (1)Universidade Federal de Viçosa, Departamento de Fitotecnia, Avenida Peter Henry Rolfs, s/nº, Campus Universitário, CEP 36570-900,
Viçosa, MG, Brasil. E-mail: heider.silva@ufv.br, pacerefo@ufv.br

Resumo - O objetivo deste trabalho foi determinar a dose ótima de $\mathrm{K}$ e seu efeito residual sobre a produtividade máxima e a qualidade de tubérculos de batata (Solanum tuberosum). O experimento 1 foi realizado em solo com baixo teor de $\mathrm{K}$ (38 $\mathrm{mg} \mathrm{dm}^{-3}$ ), em delineamento experimental de blocos ao acaso, com quatro repetições, cujos tratamentos constituíram-se de cinco doses de $\mathrm{K}-0,110,220,440$ e $880 \mathrm{~kg} \mathrm{ha}^{-1}$ de $\mathrm{K}_{2} \mathrm{O}-$, na forma de $\mathrm{KCl}$, aplicados em pré-plantio ao sulco. O experimento 2 foi realizado no mesmo local, com o teor residual do fertilizante aplicado no experimento 1. A fertilização potássica e seu efeito residual influenciaram significativamente o número, a produtividade e a matéria seca dos tubérculos. No entanto, altas doses de $\mathrm{K}$ reduziram o teor de matéria seca e a gravidade específica dos tubérculos. $\mathrm{O}$ teor residual de $\mathrm{K}$ não influenciou todos os componentes de produtividade. A dose de máxima eficiência econômica foi $393,5 \mathrm{~kg}^{-1}$ de $\mathrm{K}_{2} \mathrm{O}$, que propiciou a máxima produtividade de tubérculos comerciais de $36,2 \mathrm{Mg} \mathrm{ha}^{-1}$, no experimento 1 , e de $19,6 \mathrm{Mg} \mathrm{ha}^{-1}$, no experimento 2 .

Termos para indexação: Solanum tuberosum, fertilização, matéria seca, nutrição potássica.

\section{Potassium fertilization and its residual effect on productivity and quality of potato tubers}

\begin{abstract}
The objective of this work was to determine the optimal $\mathrm{K}$ dose and its residual effect on maximum yield and quality of potato (Solanum tuberosum) tubers. Experiment 1 was carried out in soil with low K content ( $\left.38 \mathrm{mg} \mathrm{dm}^{-3}\right)$, in a randomized complete block design, with four replicates, whose treatments consisted of five $\mathrm{K}$ rates $-0,110,220,440$, and $880 \mathrm{~kg} \mathrm{ha}^{-1} \mathrm{~K}_{2} \mathrm{O}$-, as $\mathrm{KCl}$, applied in the grooves in the pre-planting period. Experiment 2 was carried out in the same location, using the residual content of the fertilizer applied in experiment 1 . Potassium fertilization and its residual effect significantly affected the number, yield, and dry matter of tubers. However, high doses of $\mathrm{K}$ reduced the dry matter content and the specific gravity of tubers. The residual $\mathrm{K}$ content did not affect all components of productivity. The maximum economic efficiency dose was $393.5 \mathrm{~kg} \mathrm{ha}^{-1} \mathrm{~K}_{2} \mathrm{O}$, which gave $36.2 \mathrm{Mg} \mathrm{ha}^{-1}$, in experiment 1 , and $19.6 \mathrm{Mg} \mathrm{ha}^{-1}$, in experiment 2, as the maximum yields of commercial tubers.
\end{abstract}

Index terms: Solanum tuberosum, fertilization, dry matter, potassium nutrition.

\section{Introdução}

A produção e a qualidade dos tubérculos de batata requerem adequada fertilização, especialmente de $\mathrm{K}$, nutriente absorvido em grande quantidade pela planta (Nunes et al., 2006; Kumar et al., 2007). Assim, o adequado manejo da fertilização potássica é fundamental para a produção sustentável de batata (Alva et al., 2011).

A fertilização potássica afeta a produtividade e a qualidade de tubérculos de batata, principalmente em solos com baixa reserva de $\mathrm{K}$ disponível (Kavvadias, 2012). Além de aumentar a produção de tubérculos, a adição de $\mathrm{K}$ aumenta a matéria seca da parte área
(El-Sirafy et al., 2008). Entretanto, muitas pesquisas reportam ausência de efeito do K sobre a produtividade, em solos de baixa e alta disponibilidade do nutriente (Allison et al., 2001; Mohr \& Tomasiewicz, 2012).

A aplicação de $\mathrm{K}$ aumenta o número e o tamanho dos tubérculos (Mohr \& Tomasiewicz, 2012; Singh \& Lal, 2012). A produção e o número dos tubérculos não comerciais são significantemente reduzidos com o aumento das doses de K (Singh \& Lal, 2012), efeito desejável, pois incrementa o índice de colheita comercial. O teor de matéria seca e a gravidade específica dos tubérculos são importantes aspectos de qualidade influenciados pelo K (Braun et al., 2010). 
O teor de matéria seca dos tubérculos é reduzido com o aumento da fertilização potássica, principalmente com aplicação de $\mathrm{KCl}$ (Kavvadias, 2012). Também, a aplicação excessiva de $\mathrm{K}$ reduz a gravidade específica dos tubérculos, com maior efeito quando o $\mathrm{KCl}$ aplicado é comparado a uma outra fonte de K, como $\mathrm{K}_{2} \mathrm{SO}_{4}$ (Laboski \& Kelling 2007; Mohr \& Tomasiewicz, 2012). No entanto, alguns autores afirmam que há redução da gravidade específica com aplicação de K, sem diferença entre as fontes aplicadas (Davenport \& Bentley, 2001).

Vários estudos avaliaram o efeito da adubação potássica sobre a produtividade da cultura da batata. Há, porém, poucas informações sobre a cultivar 'Ágata', atualmente a principal cultivar plantada no Brasil. Espera-se com isso, evitar recomendações padronizadas e consumo de luxo de K pelas plantas, e assim otimizar a produtividade e o uso do fertilizante potássico pela planta.

O objetivo deste trabalho foi determinar a dose ótima de $\mathrm{K}$ e seu efeito residual sobre a produtividade máxima e a qualidade de tubérculos de batata (Solanum tuberosum).

\section{Material e Métodos}

Realizaram-se dois experimentos no período de junho a setembro de 2013 e de março a julho de 2014, na Universidade Federal de Viçosa (UFV), Viçosa, MG, nas coordenadas $20^{\circ} 45^{\prime} \mathrm{S}, 42^{\circ} 51^{\prime} \mathrm{W}$, e a $689,7 \mathrm{~m}$ de altitude.

Os experimentos foram conduzidos em solo Argissolo Vermelho-Amarelo câmbico (Santos et al., 2013), com as seguintes características: 512, 150 e $330 \mathrm{~g} \mathrm{~kg}^{-1}$ de argila, silte e areia, respectivamente; baixo teor de $\mathrm{K}$ disponível ( $\left.38 \mathrm{mg} \mathrm{dm}^{-3}\right) ; 13,6 \mathrm{mg} \mathrm{dm}^{-3}$ de P; 2,6, 0,70, 0,0 e 2,97 $\mathrm{cmol}_{\mathrm{c}} \mathrm{dm}^{-3} \mathrm{de}^{\mathrm{Ca}^{2+}}, \mathrm{Mg}^{2+}$, $\mathrm{Al}^{3+} \mathrm{e}^{+}+\mathrm{Al}^{3+}$, respectivamente, na camada $0-20 \mathrm{~cm}$ de profundidade. Antes de iniciar o experimento 2, o teor residual médio de $\mathrm{K}$ disponível era de 39,6 $\mathrm{mg} \mathrm{dm}{ }^{-3}$. Os teores para $\mathrm{P}, \mathrm{Ca}^{2+}, \mathrm{Mg}^{2+}, \mathrm{Al}^{3+} \mathrm{e}^{+}+\mathrm{Al}^{3+}$, respectivamente, eram $33,8 \mathrm{mg} \mathrm{dm}^{-3}$, e $3,01,0,55,0,0$ e 3,9 $\mathrm{cmol}_{\mathrm{c}} \mathrm{dm}^{-3}$.

Utilizou-se um delineamento de blocos ao acaso, com quatro repetições. No experimento 1 , os tratamentos foram cinco doses de potássio - 0, 110, 220, 440 e $880 \mathrm{~kg} \mathrm{ha}^{-1} \mathrm{de}_{2} \mathrm{O}$-, na forma de $\mathrm{KCl}(58 \%)$, aplicado em pré-plantio ao sulco. Cada parcela foi composta de quatro fileiras de oito plantas, no espaçamento $0,75 \times 0,25 \mathrm{~m}$. Como fileiras úteis, utilizaram-se apenas as duas centrais. $\mathrm{O}$ experimento 2 foi instalado no mesmo local do experimento 1 , tendo-se realizado o mesmo sorteio para a localização das parcelas que continham as cinco doses de potássio. Os tratamentos foram os teores residuais das doses aplicadas no experimento anterior.

Antes do plantio, o solo foi preparado mecanicamente. A adubação pré-plantio aplicada ao sulco foi feita com: $220 \mathrm{~kg} \mathrm{ha}^{-1} \mathrm{deN}$ (ureia); $324 \mathrm{~kg} \mathrm{ha}^{-1} \mathrm{de}_{2} \mathrm{O}_{5}$ (superfosfato simples); $20 \mathrm{~kg} \mathrm{ha}^{-1}$ de $\mathrm{Mg}$ (sulfato de magnésio); 1,1 $\mathrm{kg} \mathrm{ha}^{-1}$ de B, 2,2 $\mathrm{kg} \mathrm{ha}^{-1}$ de $\mathrm{Zn}, 2,4 \mathrm{~kg} \mathrm{ha}^{-1}$ de Cu e $195 \mathrm{~g} \mathrm{ha}^{-1}$ de Mo, nas formas de bórax, sulfato de zinco, sulfato de cobre e molibdato de sódio, respectivamente. $\mathrm{O}$ fertilizante nitrogenado foi parcelado, metade da dose foi aplicada em pré-plantio. e o restante em cobertura, à época da amontoa (21 dias após a emergência das plantas - DAE). No experimento 2, a adubação foi a mesma praticada para o experimento 1 , exceto quanto à aplicação de K. A cultivar 'Ágata' foi utilizada como batata-semente, plantada em 17/06/13 (experimento 1). No segundo experimento, o plantio ocorreu em 14/03/14, tendo-se utilizado os tubérculos colhidos no experimento 1 , os quais haviam sido armazenados em câmara fria. A amontoa foi realizada aos 21 DAE. Os experimentos foram irrigados por aspersão convencional, de acordo com o procedimento adotado por Nunes (2006). A cultura foi conduzida em campo, conforme recomendações de Fontes (2005), e o controle de pragas e doenças foi realizado com a aplicação de defensivos químicos com os ingredientes ativos carbofurano, mancozebe, oxicloreto de cobre e deltametrina.

Aos 88 DAE (23/9/13) e aos 84 DAE (28/7/14), nos experimentos 1 e 2, respectivamente, os tubérculos da área útil foram colhidos. Após a colheita, os tubérculos foram classificados, quantificados e pesados. Os tubérculos foram classificados de acordo com o diâmetro transversal (Brasil, 1995) em: classe I, diâmetro maior ou igual a $8,5 \mathrm{~cm}$; classe II, maior que 4,5 e menor que $8,5 \mathrm{~cm}$; classe III, maior que 3,3 e menor que $4,5 \mathrm{~cm}$; e classe IV, menor ou igual a $3,3 \mathrm{~cm}$. A produção comercial foi obtida com a soma das classes II e III, sem a classe I de tubérculos, que não foi produzida. Os tubérculos não comerciais foram considerados aqueles pertencentes à classe IV, além dos podres, atacados por pragas e doenças, com defeitos de esverdeamento, embonecamento ou rachaduras. 
Após a colheita, em uma amostra de seis tubérculos comerciais por parcela, determinou-se a matéria seca para todas as classes dos tubérculos. Os tubérculos foram cortados e mantidos em placas de Petri para a secagem parcial. Posteriormente, foram secos em estufa de circulação forçada de ar, a $70^{\circ} \mathrm{C}$ até a obtenção de massa constante. Com os valores de matéria seca, determinou-se o teor de matéria seca nos tubérculos.

A gravidade específica foi determinada em amostra de seis tubérculos comerciais por parcela, pelo método da flutuação em solução salina, descrito por Reis Júnior (1995).

Os dados foram submetidos à análise de variância e regressão, com o programa estatístico SAS, versão 9.4 (SAS Institute Inc., Cary, NC, EUA). Como critério para a seleção dos modelos, adotou-se o significado biológico, a significância dos coeficientes de regressão, tendo-se admitido, para o teste t, a probabilidade de até $10 \%$ e o coeficiente de determinação $\mathrm{R}^{2}=\mathrm{SQ}_{\text {regressãol }}$ $\mathrm{SQ}_{\text {tratamento. }}$.

Para a obtenção da dose de $\mathrm{K}_{2} \mathrm{O}$, quanto à produção de máxima eficiência física (MEF), igualou-se a zero a primeira derivada da equação ajustada da produção comercial de tubérculos. A dose de $\mathrm{K}_{2} \mathrm{O}$ para a máxima eficiência econômica (MEE) foi obtida ao se igualar a primeira derivada da equação à relação entre o preço médio do $\mathrm{K}_{2} \mathrm{O}$, contido no $\mathrm{KCl}$, e o preço da batata durante o período de cinco anos (setembro de 2008 a setembro 2013). Os preços foram obtidos no Instituto... (2014). A relação média de preço ( $\mathrm{kg}$ de $\mathrm{KCl}: \mathrm{kg}$ de batata) foi de 2,29, referente ao preço da batata - de R\$ $0,79 \mathrm{~kg}^{-1}$ - e o preço do $\mathrm{K}$, na forma de cloreto de potássio, de $\mathrm{R} \$ 1,81 \mathrm{~kg}^{-1}\left(3,23 \mathrm{~kg}^{-1}\right.$ de $\mathrm{K}_{2} \mathrm{O}$ ).

\section{Resultados e Discussão}

Houve efeito da fertilização potássica (Tabela 1) e do potássio residual (Tabela 2) sobre o número de tubérculos por classes. Os tubérculos da classe I $(>85 \mathrm{~mm})$ não foram produzidos nos dois experimentos, semelhantemente ao constatado por Fontes et al. (2012), em experimento com espaçamento e critério de recomendação de adubação para a batata. A produção de tubérculos classe I é mais influenciada pela alta disponibilidade de N, tal como observado em condições de adubação orgânica (100-145 kg ha-1 de N) associadas a solo com alta disponibilidade de $\mathrm{NO}_{3}-\mathrm{N}$, além do efeito de cultivares (Haase et al., 2007).

$\mathrm{O}$ aumento das doses de $\mathrm{K}$ elevou linearmente o número de tubérculos da classe II (45-85 mm), nos dois experimentos (Tabela 1 e 2). $\mathrm{O}$ aumento linear do número de tubérculos grandes, com a aplicação de $\mathrm{K}$, é relatado na literatura por Sing \& Lal (2012) e Bansal \& Trehan (2011).

O número de tubérculos da classe III (entre 33 e $45 \mathrm{~mm}$ ) aumentou de forma quadrática com a fertilização potássica, entretanto, não houve efeito do potássio residual (Tabela 1 e 2). Recentemente, Sing \& Lal (2012) mostraram que o número de tubérculos médios é aumentado com a aplicação de até $150 \mathrm{~kg} \mathrm{ha}^{-1}$ de $\mathrm{K}$, em solo com média disponibilidade de $\mathrm{K}\left(89 \mathrm{mg} \mathrm{dm}^{-3}\right)$. Essa dose de $\mathrm{K}$ é inferior à dose de $379 \mathrm{~kg} \mathrm{ha}^{-1} \mathrm{~K}_{2} \mathrm{O}$, estimada nesta pesquisa como ótima para a máxima produtividade de tubérculos da classe III, em solo com baixa disponibilidade de $\mathrm{K}$ $\left(38 \mathrm{mg} \mathrm{dm}^{-3}\right)$. Essa diferença entre as doses de $\mathrm{K}$ é explicada pela disponibilidade do nutriente no solo, de modo que os solos pobres em $\mathrm{K}$ necessitam de maiores doses de fertilizantes (Allison et al., 2001).

Tabela 1. Equações de regressão para o número, produtividade, matéria seca dos tubérculos nas classes II, III, IV, e produtividade comercial e total de batata, em resposta à aplicação de potássio.

\begin{tabular}{|c|c|c|}
\hline Variável & Equações de regressão & $\mathrm{R}^{2}$ \\
\hline \multicolumn{3}{|c|}{ Número de tubérculos classificados (unidade por planta) } \\
\hline Classe II & $\hat{\mathrm{Y}}=3,19750+0,00203 * * \mathrm{~K}$ & 0,9742 \\
\hline Classe III & $\hat{\mathrm{Y}}=4,83754+0,00779 * * \mathrm{~K}-0,00001053 * * \mathrm{~K}^{2}$ & 0,9974 \\
\hline Classe IV & $\hat{\mathrm{Y}}=7,900025-0,00423 * \mathrm{~K}$ & 0,8463 \\
\hline Comercial & $\hat{\mathrm{Y}}=7,96043+0,24024 *(\mathrm{~K})^{0,5}-0,00733 * \mathrm{~K}$ & 0,9552 \\
\hline Total & $\hat{\mathrm{Y}}=15,37192+0,00819 * \mathrm{~K}-0,00001282 * \mathrm{~K}^{2}$ & 0,9801 \\
\hline \multicolumn{3}{|c|}{ Produtividade de tubérculos classificados $\left(\mathrm{Mg} \mathrm{ha}^{-1}\right)$} \\
\hline Classe II & $\hat{\mathrm{Y}}=16,31758+0,01158 * \mathrm{~K}$ & 0,7971 \\
\hline Classe III & $\hat{\mathrm{Y}}=10,75646+0,01497 * * \mathrm{~K}-0,00001956 * * \mathrm{~K}^{2}$ & 0,9952 \\
\hline Classe IV & $\hat{\mathrm{Y}}=2,52831+0,14473 *(\mathrm{~K})^{0,5}-0,00476 * \mathrm{~K}$ & 0,9636 \\
\hline Comercial & $\hat{\mathrm{Y}}=23,67764+1,16309 *(\mathrm{~K})^{0,5}-0,02701 * \mathrm{~K}$ & 0,9811 \\
\hline Total & $\hat{\mathrm{Y}}=26,16932+1,15932 *(\mathrm{~K})^{0,5}-0,02651 * \mathrm{~K}$ & 0,9771 \\
\hline \multicolumn{3}{|c|}{ Matéria seca de tubérculos classificados $\left(\mathrm{Mg} \mathrm{ha}^{-1}\right)$} \\
\hline Classe II & $\hat{\mathrm{Y}}=2,48954+0,00295 * * \mathrm{~K}-0,00000188 * \mathrm{~K}^{2}$ & 0,9963 \\
\hline Classe III & $\hat{\mathrm{Y}}=1,94154+0,00088394^{\circ} \mathrm{K}-0,00000186^{*} \mathrm{~K}^{2}$ & 0,9879 \\
\hline Classe IV & $\hat{\mathrm{Y}}=0,44231+0,01770 *(\mathrm{~K})^{0,5}-0,00062787^{*} \mathrm{~K}$ & 0,9749 \\
\hline Comercial & $\hat{\mathrm{Y}}=4,42323+0,00407 * * * \mathrm{~K}-0,00000399 * * * \mathrm{~K}^{2}$ & 0,9998 \\
\hline Total & $\hat{\mathrm{Y}}=4,90292+0,00410 * \mathrm{~K}-0,00000417 * \mathrm{~K}^{2}$ & 0,9757 \\
\hline
\end{tabular}


O número de tubérculos da classe IV (inferior a $33 \mathrm{~mm}$ ), não comerciais, foi reduzido com o aumento da dose de K no experimento 1 (Tabela 1). Diferentemente, o teor residual de $\mathrm{K}$ não afetou a classe não comercial (Tabela 2). Esse resultado indica que o aumento da disponibilidade de K contribui para o aumento do número de tubérculos das classes II e III e para a redução do número de tubérculos da classe IV. Essa diferença do número dos tubérculos com o incremento de $\mathrm{K}$ pode ser resultado da influência sobre a fotossíntese e conversão de assimilados (Zörb et al., 2014), o que contribui para o rápido crescimento dos tubérculos (Sing \& Lal, 2012).

Em geral, o número de tubérculos comerciais e totais foi influenciado positivamente pela fertilização potássica, e as equações de regressão que melhor se ajustaram aos dados foram os modelos raiz quadrática e quadráticos, respectivamente (Tabela 1). Entretanto, o teor de potássio residual incrementou apenas a classe de tubérculos comerciais, composta principalmente

Tabela 2. Equações de regressão para o número, produtividade, matéria seca dos tubérculos nas classes II, III, IV, produtividade comercial e total, teor de matéria seca e gravidade específica dos tubérculos em resposta ao potássio residual.

\begin{tabular}{|c|c|c|}
\hline Variável & Equação de regressão & $\mathrm{R}^{2}$ \\
\hline & \multicolumn{2}{|c|}{ Número de tubérculos classificados por planta } \\
\hline Classe II & $\hat{\mathrm{Y}}=1,18800+0,00304 * * \mathrm{~K}$ & 0,9689 \\
\hline Classe III & $\hat{\mathrm{Y}}=3,41$ & - \\
\hline Classe IV & $\hat{\mathrm{Y}}=4,75$ & - \\
\hline Comercial & $\hat{\mathrm{Y}}=4,77100+0,00254 * \mathrm{~K}$ & 0,8814 \\
\hline \multirow[t]{2}{*}{ Total } & $\hat{\mathrm{Y}}=10,35$ & - \\
\hline & \multicolumn{2}{|c|}{ Produtividade de tubérculos classificados $\left(\mathrm{Mg} \mathrm{ha}^{-1}\right)$} \\
\hline Classe II & $\hat{\mathrm{Y}}=4,08450+0,01999 * * \mathrm{~K}$ & 0,9807 \\
\hline Classe III & $\hat{\mathrm{Y}}=7,78$ & - \\
\hline Classe IV & $\hat{\mathrm{Y}}=3,89025-0,00248^{* *} \mathrm{~K}$ & 0,9368 \\
\hline Comercial & $\hat{Y}=12,49200+0,01811 * K$ & 0,9903 \\
\hline \multirow[t]{2}{*}{ Total } & $\hat{\mathrm{Y}}=16,37675+0,0563 * * * \mathrm{~K}$ & 0,9900 \\
\hline & \multicolumn{2}{|c|}{ Matéria seca de tubérculos classificados $\left(\mathrm{Mg} \mathrm{ha}^{-1}\right)$} \\
\hline Classe II & $\hat{\mathrm{Y}}=0,76800+0,00382 * * * \mathrm{~K}$ & 0,9873 \\
\hline Classe III & $\hat{\mathrm{Y}}=1,47$ & - \\
\hline Classe IV & $\hat{\mathrm{Y}}=0,65903-0,00040614 * \mathrm{~K}$ & 0,8232 \\
\hline Comercial & $\hat{\mathrm{Y}}=2,32975+0,00353 * * * \mathrm{~K}$ & 0,9842 \\
\hline \multirow[t]{2}{*}{ Total } & $\hat{\mathrm{Y}}=3,05255+0,00310^{* *} \mathrm{~K}$ & 0,9797 \\
\hline & \multicolumn{2}{|c|}{ Características pós-colheita dos tubérculos } \\
\hline Teor MS (\%) & $\hat{\mathrm{Y}}=18,97$ & - \\
\hline Gravidade específica & $\hat{\mathrm{Y}}=1,0743$ & - \\
\hline
\end{tabular}

$* * *, * *$ e $*$ Significativo pelo teste $\mathrm{t}$, a $0,1,1$ e $5 \%$ de probabilidade, respectivamente. pela classe II (Tabela 2). O incremento do número de tubérculos de batata, com a fertilização potássica, ocorre principalmente em solo com baixo teor de $\mathrm{K}$ (Kavvadias et al., 2012; Kang et al., 2014), como confirmado no presente trabalho em solo com teor inicial de $\mathrm{K}$ de $38 \mathrm{mg} \mathrm{dm}^{-3}$, valor interpretado como baixo para a batata.

A produtividade de tubérculos em todas as classes foi influenciada pela fertilização potássica no experimento 1 (Tabela 1). O residual potássico aumentou linearmente a produtividade de tubérculo das classes II, comercial e total, e reduziu a da classe IV (Tabela 2). Esses resultados são consistentes com os reportados por Sing \& Lal (2012) que, ao estudar o efeito do $\mathrm{K}$ sobre a produtividade de tubérculos, constataram o aumento da produtividade de tubérculos grandes e médios.

A resposta positiva em produtividade de tubérculos, com a aplicação de $\mathrm{K}$, depende de diversos fatores como cultivar, disponibilidade de K no solo e fontes de fertilizantes. Em Minas Gerais, as recomendações de $\mathrm{K}$ variam de $350 \mathrm{~kg} \mathrm{ha}^{-1}$ de $\mathrm{K}_{2} \mathrm{O}$, em solos com baixa disponibilidade $\left(<21 \mathrm{mg} \mathrm{dm}^{-3} \mathrm{de} \mathrm{K}\right)$, a $150 \mathrm{~kg} \mathrm{ha}^{-1} \mathrm{de}$ $\mathrm{K}_{2} \mathrm{O}$, naqueles com alta disponibilidade $\left(>140 \mathrm{mg} \mathrm{dm}^{-3}\right.$ de K). Em regiões do Canadá, em solo com teor de $\mathrm{K}$ superior a $200 \mathrm{mg} \mathrm{dm}^{-3}$, não é recomendada aplicação de K (Mohr \& Tomasiewicz, 2012). Da mesma forma, Allison et al. (2001) sugerem, para solos com teor de K menor do que $120 \mathrm{mg} \mathrm{dm}^{-3}$, que a aplicação não exceda $210 \mathrm{~kg} \mathrm{ha}^{-1}$ de $\mathrm{K}$.

A produtividade comercial e total aumentou de forma linear com o aumento do teor de potássio residual (Figura $1 \mathrm{~B}$ ). O postássio residual da aplicação de 393,5 $\mathrm{kg} \mathrm{ha}^{-1}$ de $\mathrm{K}_{2} \mathrm{O}$, dose de MEE aplicada no experimento 1 , proporcionou a produtividade comercial de 19,6 $\mathrm{Mg} \mathrm{ha}^{-1}$ (Tabela 2). O K residual pode aumentar a produtividade da batata, entretanto, esse efeito positivo está associado à capacidade trocável de $\mathrm{K}$ do solo, conforme Allison et al., 2001, que estudaram a reposta da batata à fertilização potássica em 33 experimentos e evidenciaram o pouco benefício do teor residual de $\mathrm{K}$ sobre a produtividade de tubérculos. Isso se explica, principalmente, pelo alto teor de $\mathrm{K}$ inicial do solo, que resulta até mesmo em ausência de resposta à fertilização.

As doses de 392,5 e de $880 \mathrm{~kg} \mathrm{ha}^{-1}$ de $_{2} \mathrm{O}$ propiciaram a maior produtividade comercial de tubérculos nos experimentos 1 e 2, que foi de 36,1 e $28,4 \mathrm{Mg} \mathrm{ha}^{-1}$, 
respectivamente. Aplicando-se $880 \mathrm{~kg} \mathrm{ha}^{-1}$ apenas no primeiro plantio, as produtividades seriam de 34,4 e $28,4 \mathrm{Mg} \mathrm{ha}^{-1}$, ou seja, no conjunto dos dois experimentos, seriam obtidos $62,8 \mathrm{Mg} \mathrm{ha}^{-1}$, isto é $71 \mathrm{~kg}$ de tubérculos por $\mathrm{kg}$ de $\mathrm{K}_{2} \mathrm{O}$.

As doses de $\mathrm{K}_{2} \mathrm{O}$ recomendadas para a batata podem ser estimadas por meio da quantidade extraída de $\mathrm{K}$ na matéria seca, para alcance de determinada produtividade de tubérculos, conforme Cogo et al. (2006), que estimaram, em condições de abrigo telado e substrato orgânico, que a produtividade de $35 \mathrm{Mg} \mathrm{ha}^{-1}$ de tubérculos da cultivar 'Asterix' extraem 235,2 $\mathrm{kg} \mathrm{ha}^{-1}$ de $\mathrm{K}$ ou $283,8 \mathrm{~kg} \mathrm{ha}^{-1}$ de $\mathrm{K}_{2} \mathrm{O}$. Para a extração desta quantidade de $\mathrm{K}$, considerando-se o suprimento
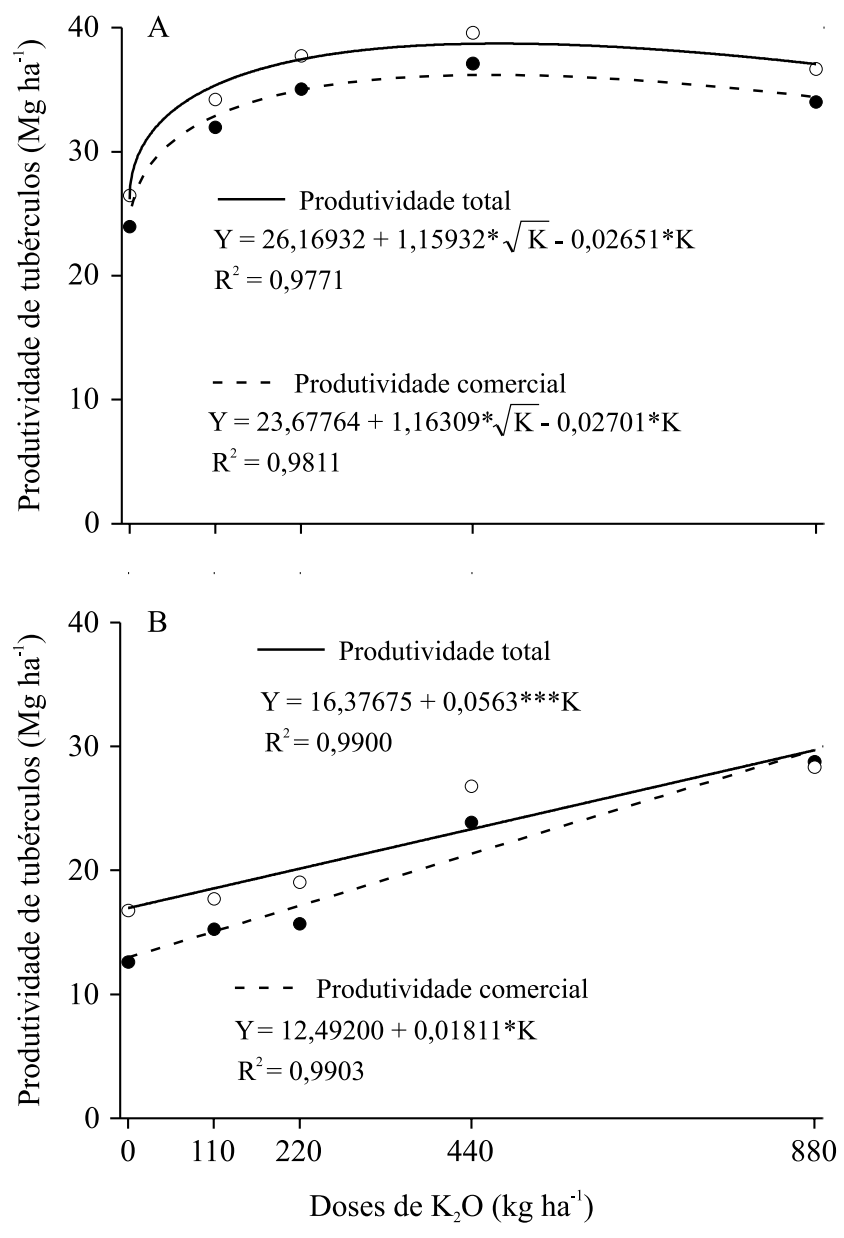

Figura 1. Relação entre a produtividade de tubérculos de batata e doses de potássio (A) e teor de potássio residual (B). $* * *$ e $*$ Significativo pelo teste $\mathrm{t}$, a 0,1 e $5 \%$ de probabilidade, respectivamente. pelo solo de $91,5 \mathrm{~kg} \mathrm{ha}^{-1}$ de $\mathrm{K}_{2} \mathrm{O}$ (teor de $\mathrm{K}$ no solo de $38 \mathrm{mg} \mathrm{dm}^{-3}$ ), seriam necessários $192,2 \mathrm{~kg} \mathrm{ha}^{-1}$ de $\mathrm{K}_{2} \mathrm{O}$, ou seja, 384,4 $\mathrm{kg} \mathrm{ha}^{-1}$ de $\mathrm{K}_{2} \mathrm{O}$, assumindo-se que é de $50 \%$ a eficiência de recuperação do fertilizante potássico (Sing \& Lal, 2012). Este valor é próximo dos $393,5 \mathrm{~kg} \mathrm{ha}^{-1}$ de $\mathrm{K}_{2} \mathrm{O}$ encontrado no experimento 1.

$\mathrm{A}$ aplicação de $\mathrm{K}$ e o teor de potássio residual aumentaram a produção de matéria seca dos tubérculos da classe II, seguindo o mesmo padrão de resposta da produtividade comercial (Tabela 1 e 2). Do mesmo modo, houve efeito positivo do aumento das doses de $\mathrm{K}$ sobre a matéria seca dos tubérculos da classe III, cuja resposta seguiu o modelo quadrático e um padrão similar ao observado para o número e produção de tubérculos (Tabela 1). Todavia, o efeito residual da adubação potássica não afetou a produção de matéria seca dessa classe de tubérculos (Tabela 2).

Embora a aplicação de $\mathrm{K}$ tenha reduzido o número de tubérculos não comerciais, a matéria seca produzida pelos tubérculos não comerciais aumentou levemente até atingir um ponto de máximo e decresceu posteriormente (Tabela 1). No entanto, a matéria seca produzida nessa classe reduziu-se linearmente com o aumento do teor de potássio residual (Tabela 2). A matéria seca, geralmente, é a medida líquida da resposta da batata à fertilização (Allison et al., 2001).

A quantidade de matéria seca dos tubérculos comerciais e dos tubérculos totais também foi influenciada pela fertilização potássica e pelo potássio residual (Tabelas 1 e 2). A aplicação de $393,5 \mathrm{~kg} \mathrm{ha}^{-1}$ de $\mathrm{K}_{2} \mathrm{O}$, dose de MEE, aumentou em $22 \%$ a matéria seca de tubérculos comerciais em comparação ao tratamento-controle. $\mathrm{O}$ efeito residual dessa dose de $\mathrm{K}$ permitiu o aumento de $60,0 \%$ da produção de matéria seca da classe comercial, em relação ao tratamento-controle. Outros autores também relatam o efeito do $\mathrm{K}$ sobre a produção da matéria seca de tubérculos (Allison et al., 2001; Sing \& Lal, 2012), embora com valores maiores de produção de matéria seca, o que é explicado pela maior produtividade de tubérculos.

A fertilização potássica reduziu a percentagem de matéria seca pós-colheita dos tubérculos (Figura $2 \mathrm{~A}$ ). A aplicação de 0 e $880 \mathrm{~kg} \mathrm{ha}^{-1}$ de $\mathrm{K}_{2} \mathrm{O}$ reduziu o teor de matéria seca dos tubérculos de 18,2 para $14,1 \%$, todavia, dentro dos valores adequados para a cultivar 'Ágata' (Braun et al., 2010). Com a dose de 392,5 ha-1 de $\mathrm{K}_{2} \mathrm{O}$, dose de MEE, a percentagem de matéria seca 
dos tubérculos pós-colheita foi de 15,04\%. Não houve efeito do potássio residual sobre o teor de matéria seca dos tubérculos (Tabela 2). O efeito negativo do K sobre o teor de matéria seca dos tubérculos foi relatado em outros trabalhos (Haase et al., 2007), com maior efeito quando o $\mathrm{K}$ foi aplicado na forma de cloreto de potássio do que quando aplicado na forma de sulfato de potássio (Allison et al., 2001).

A percentagem de matéria seca é característica importante, indicativa da qualidade dos tubérculos pós-colheita, especialmente para a indústria de processamento (Haase et al., 2007; Braun et al., 2010).
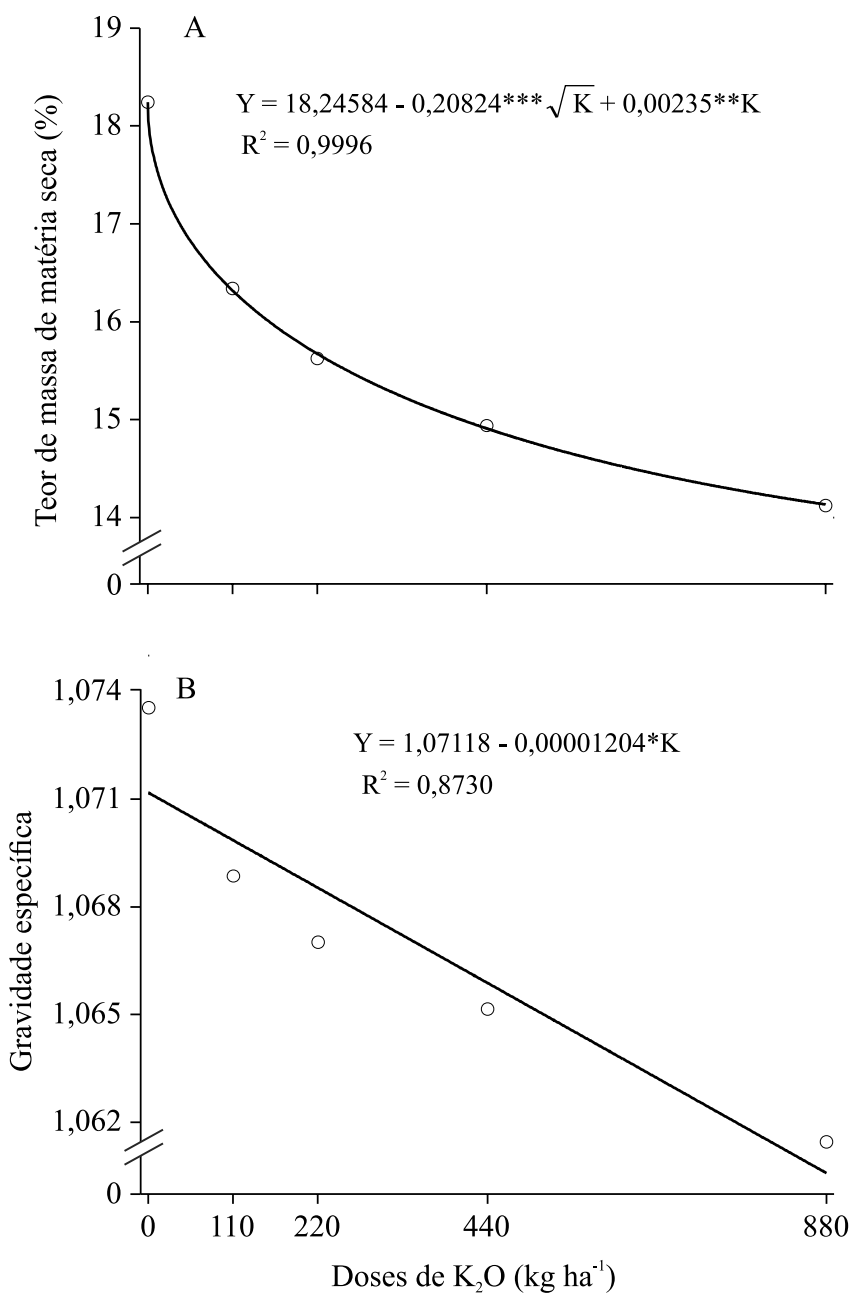

Figura 2. Teor de matéria seca (A) e gravidade específica dos tubérculos (B), em resposta a doses de potássio, no experimento $1 . * * *, * *$ e $*$ Significativo pelo teste $\mathrm{t}, 0,1,1 \mathrm{e}$ $5 \%$ de probabilidade, respectivamente.
A gravidade específica dos tubérculos foi reduzida com a aplicação do $\mathrm{K}$, de 1,073 na ausência de fertilização potássica, para 1,061 com a aplicação de $880 \mathrm{~kg} \mathrm{ha}^{-1}$ de $\mathrm{K}_{2} \mathrm{O}$ (Figura 2). O potássio residual não influenciou a gravidade específica (Tabela 2).Todavia, Reis Júnior (1995) obteve aumento da gravidade específica, com o aproveitamento da adubação residual de $\mathrm{K}$ em aplicação de $\mathrm{K}_{2} \mathrm{SO}_{4}$. As fontes de $\mathrm{K}$ afetam distintamente a atividade de enzimas associadas ao acúmulo de matéria seca nos tubérculos. $\mathrm{O}$ ânion $\mathrm{Cl}^{-}$ inibe e $\mathrm{O} \mathrm{SO}_{4}^{-}$aumenta a atividade dessas enzimas (Kumar et al., 2007), o que pode explicar os diferentes resultados.

Em geral, o aumento da dose de $\mathrm{K}$ reduz a gravidade específica dos tubérculos (Davenport, 2000), embora com efeito distinto quanto à fonte aplicada (Davenport \& Bentley, 2001). A redução da gravidade específica com a aplicação de $\mathrm{K}$, principalmente na forma de cloreto, decorre do maior índice salino do fertilizante e maior absorção de K, que aumenta a absorção de água dos tubérculos (Laboski \& Kelling, 2007).

\section{Conclusões}

1. A fertilização potássica aumenta o número, a produtividade e a produção de matéria seca dos tubérculos; todavia o teor residual de potássio não influencia todos os componentes de produtividade.

2. Para a máxima eficiência econômica, é necessário aplicar 393,5 kg ha-1 de $\mathrm{K}_{2} \mathrm{O}$, o que propicia a obtenção da produtividade de tubérculos de $36,1 \mathrm{Mg} \mathrm{ha}^{-1}$.

3. O aumento das doses de potássio reduz a qualidade pós-colheita da batata, porém, o potássio residual não tem efeito sobre a qualidade dos tubérculos.

\section{Agradecimentos}

AoConselho Nacional de Desenvolvimento Científico e Tecnológico (CNPq) e à Fundação de Amparo à Pesquisa do Estado de Minas Gerais (Fapemig), pelo apoio financeiro e pela concessão de bolsa.

\section{Referências}

ALLISON, M.F.; FOWLER, J.H.; ALLEN, E.J. Responses of potato (Solanum tuberosum) to potassium fertilizers. The Journal of Agricultural Science, v.136, p.407-426, 2001. DOI: 10.1017/ S0021859601008863.

ALVA, A.; FAN, M.; QING, C.; ROSEN, C.; REN, H. Improving nutrient-use efficiency in Chinese potato production: experiences 
from the United States. Journal of Crop Improvement, v.25, p.46-85, 2011. DOI: 10.1080/15427528.2011.538465.

BANSAL, S.K.; TREHAN, S.P. Effect of potassium on yield and processing quality attributes of potato. Karnataka Journal of Agricultural Sciences, v.24, p.48-54, 2011.

BRASIL. Ministério da Agricultura, Pecuária e Abastecimento. Portaria n. ${ }^{\circ}$ 69, de 21 de fevereiro de 1995. [Aprova norma de identidade, qualidade, acondicionamento e embalagem da batata, para fins de comercialização]. Diário Oficial [da] República Federativa do Brasil, Brasília, 23 fev. 1995. Seção 1, p.2560-2561.

BRAUN, H.; FONTES, P.C.R.; FINGER, F.L.; BUSATO, C.; CECON, P.R. Carboidratos e matéria seca de tubérculos de cultivares de batata influenciados por doses de nitrogênio. Ciência e Agrotecnologia, v.34, p.285-293, 2010. DOI: 10.1590/ S1413-70542010000200003.

COGO, C.M; ANDRIOLO, J.L.; BISOGNIN, D.A.; GODOI, R. dos S.; BORTOLOTTO, O.C.; LUZ, G.L. da. Relação potássio-nitrogênio para o diagnóstico e manejo nutricional da cultura da batata. Pesquisa Agropecuária Brasileira, v.41, p.1781-1786, 2006. DOI: 10.1590/S0100-204X2006001200013.

DAVENPORT, J.R. Potassium and specific gravity of potato tubers. Better Crops with Plant Food, v.84, p.14-15, 2000.

DAVENPORT, J.R.; BENTLEY, E.M. Does potassium fertilizer form, source, and time of application influence potato yield and quality in the Columbia Basin? American Journal of Potato Research, v.78, p.311-318, 2001. DOI: 10.1007/BF02875696.

EL-SIRAFY, Z.M.; ABBADY, K.A.; EL-GHAMRY, A.M.; EL-DISSOKY, R.A. Potato yield quality, quantity and profitability as affected by soil and foliar potassium application. Research Journal of Agriculture and Biological Sciences, v.4, p.912-922, 2008 .

FONTES, P.C.R.; NUNES, J.C.S.; MOREIRA, M.A. Produção classificada de batata em resposta ao espaçamento e critério de recomendação da adubação. Bioscience Journal, v.28, p.404-412, 2012.

FONTES, P.C.R. Cultura da batata. In: FONTES, P.C.R. (Ed). Olericultura: teoria e prática. Viçosa: UFV, 2005. p.323-343.

HAASE, T.; SCHÜLER, C.; HEß, J. The effect of different $\mathrm{N}$ and $\mathrm{K}$ sources on tuber nutrient uptake, total and graded yield of potatoes (Solanum tuberosum L.) for processing. European Journal of Agronomy, v.26, p.187-197, 2007. DOI: 10.1016/j. eja.2006.09.008.
INSTITUTO DE ECONOMIA AGRÍCOLA. Instituto de Economia Agrícola. 2014. Disponível em: <http://www.iea. sp.gov.br>. Acesso em: 14 maio 2014.

KANG, W.; FAN, M.; MA, Z.; SHI, X.; ZHENG, H. Luxury absorption of potassium by potato plants. American Journal of Potato Research, v.91, p.573-578, 2014. DOI: 10.1007/ s12230-014-9386-8.

KAVVADIAS, V.; PASCHALIDIS, C.; AKRIVOS, G.; PETROPOULOS, D. Nitrogen and potassium fertilization responses of potato (Solanum tuberosum) cv. Spunta. Communications in Soil Science and Plant Analysis, v.43, p.176-189, 2012. DOI: 10.1080/00103624.2012.634711.

KUMAR, P.; PANDEY, S.K.; SINGH, B.P.; SINGH, S.V.; KUMAR, D. Influence of source and time of potassium application on potato growth, yield, economics and crisp quality. Potato Research, v.50, p.1-13, 2007. DOI: 10.1007/s11540-007-9023-8.

LABOSKI, C.A.M.; KELLING, K.A. Influence of fertilizer management and soil fertility on tuber specific gravity: a review. American Journal of Potato Research, v.84, p.283-290, 2007. DOI: 10.1007/BF02986240.

MOHR, R.M.; TOMASIEWICZ, D.J. Effect of rate and timing of potassium chloride application on the yield and quality of potato (Solanum tuberosum L. 'Russet Burbank'). Canadian Journal of Plant Science, v.92, p.783-794, 2012. DOI: 10.4141/cjps2011-195.

NUNES, J.C.S.; FONTES, P.C.R.; ARAÚJO, E.F.; SEDIYAMA, C. Potato plant growth and macronutrient uptake as affected by soil tillage and irrigation systems. Pesquisa Agropecuária Brasileira, v.41, p.1787-1792, 2006. DOI: 10.1590/S0100204X2006001200014.

REIS JÚNIOR, R. dos A. Produção, qualidade de tubérculos e teores de potássio no solo e no pecíolo de batateira em resposta à adubação potássica. 1995. 108p. Dissertação (Mestrado) Universidade Federal de Viçosa, Viçosa.

SANTOS, H.G. dos; JACOMINE, P.K.T.; ANJOS, L.H.C. dos; OLIVEIRA, V.A. de; LUMBRERAS, J.F.; COELHO, M.R.; ALMEIDA, J.A. de; CUNHA, T.J.F.; OLIVEIRA, J.B. de. Sistema brasileiro de classificação de solos. 3.ed. rev. e ampl. Brasília: Embrapa, 2013. 353p.

SINGH, S.K.; LAL, S.S. Effect of potassium nutrition on potato yield, quality and nutrient use efficiency under varied levels of nitrogen application. Potato Journal, v.39, p.155-165, 2012.

ZÖRB, C.; SENBAYRAM, M.; PEITER, E. Potassium in agriculture - status and perspectives. Journal of Plant Physiology, v.171, p.656-669, 2014. DOI: 10.1016/j.jplph.2013.08.008.

\footnotetext{
Recebido em 13 de janeiro de 2016 e aprovado em 23 de maio de 2016
} 